\title{
Influencia de doses de potássio nos teores de macronutrientes em plantas e sementes de alface
}

\author{
Cristiaini Kano ${ }^{1}$; Antonio Ismael Inácio Cardoso²; Roberto L Villas Bôas ${ }^{3}$
}

${ }^{1}$ APTA - Agência Paulista de Tecnologia dos Agronegócios, C. Postal 01, 13910-000 Monte Alegre do Sul-SP; ${ }^{2}$ UNESP-FCA, Depto. Produção Vegetal, Setor Horticultura, C. Postal 237, 18610-307 Botucatu-SP; ${ }^{3}$ UNESP-FCA, Depto. Recursos Naturais ,Setor Ciência do Solo; criskano@hotmail.com; ismaeldh@fca.unesp.br

\section{RESUMO}

Avaliou-se a influência de doses de potássio aplicadas em cobertura nos teores de nutrientes em plantas de alface cultivada para produção de sementes. $\mathrm{O}$ delineamento experimental utilizado foi blocos casualizados, com cinco tratamentos $(0,0 ; 1,0 ; 1,5 ; 2,0$ e 2,5 g planta ${ }^{-1}$ de $\mathrm{K}_{2} \mathrm{O}$ ) e seis repetições. Os dados foram submetidos à análise de variância e à análise de regressão. Somente os teores de potássio e magnésio determinados na matéria seca da parte aérea das plantas foram influenciados significativamente pelas doses de potássio testadas, em que para o teor de potássio ocorreu aumento linear e para o de magnésio houve redução também linear. Conclui-se que os tratamentos testados não interferiram de forma significativa nos teores de macronutrientes das sementes, apesar de ter modificado os teores de potássio e de magnésio na matéria seca da parte aérea das plantas de alface, cultivar Verônica.

\begin{abstract}
Macronutrient content in lettuce affected by potassium side dressing

The influence of potassium rates applied in side dressing was evaluated on the nutrient content of lettuce plants cultivated for seed production. The experiment was carried out in randomized complete blocks, with five treatments $(0.0 ; 1.0 ; 1.5 ; 2.0$ and $2.5 \mathrm{~g}$ plant-1 of K2O) and six replications. Only the potassium and the magnesium content in the dry matter of the plant aboveground part was affected by the treatments. The potassium content increased and the magnesium content decreased, both linearly, as an effect of the application of increasing potassium rates. Also, despite of the effect on the plant potassium content, the treatments did not affect the seed macronutrient content.
\end{abstract}

Keywords: Lactuca sativa L., potassium, nutrients content.

Palavras-chave: Lactuca sativa L., potássio, concentração de nutrientes, sementes.

(Recebido para publicação em 7 de janeiro de 2009; aceito em 5 de agosto de 2010) (Received on January 7, 2009; accepted on August 5, 2010)

\begin{abstract}
$A^{t}$ tendência atual do sistema de exploração agrícola tem sido aumentar a produtividade das culturas associada às reduções nos custos de produção. Para isso, é necessário que as práticas culturais relacionadas aos tratamentos fitossanitários e às adubações sejam eficientes. $\mathrm{O}$ conhecimento sobre o conteúdo de nutrientes nas plantas é importante para avaliar a capacidade de remoção de nutrientes de cada cultura. Esta informação pode ser utilizada na definição das recomendações econômicas de adubação (Raij et al., 1996).

Uma planta bem nutrida produzirá maior número de sementes. No início da fase reprodutiva, as exigências nutricionais, para a maioria das espécies, tornam-se mais intensa, sendo mais crítica por ocasião da formação das sementes, quando ocorre considerável translocação de nutrientes, como potássio e nitrogênio. A boa formação do embrião
\end{abstract}

e dos tecidos de reserva, assim como sua composição química, dependem de uma adequada disponibilidade de nutrientes no substrato de crescimento das plantas, o que certamente irá influenciar o metabolismo e o vigor da semente (Carvalho \& Nakagawa, 2000).

Ao lado do nitrogênio, o potássio é um dos elementos mais extraídos pelas plantas e sua deficiência ocasiona reduções no crescimento e na formação da "cabeça" de alface. Em quantidades adequadas, o potássio desempenha várias funções na planta, tais como: controle da turgidez celular, ativação de enzimas envolvidas na respiração e fotossíntese, regulagem dos processos de abertura e fechamento de estômatos, transporte de carboidratos, transpiração, resistência à geada, seca, salinidade e às doenças; aumentar a resistência ao acamamento, além de estar diretamente associado à qualidade dos produtos agrícolas (Ma- lavolta, 1980; Marschner, 1995; Davis et al., 1997).

No Estado de São Paulo, Raij et al. (1996) recomendam para produção de alface (produção comercial de folhas) as quantidades de $150 ; 100$ e $50 \mathrm{~kg} \mathrm{ha}^{-1}$ de $\mathrm{K}_{2} \mathrm{O}$, quando o teor de $\mathrm{K}^{+}$trocável no solo for de 0 a 1,5; de 1,6 a 3,0 e maior que 3,0 $\mathrm{mmol}_{\mathrm{c}} \mathrm{dm}^{-3}$, respectivamente. Recomendação ligeiramente diferente é apresentada por Filgueira (2003) que indica doses de até $90 \mathrm{~kg} \mathrm{ha}^{-1}$ de $\mathrm{K}_{2} \mathrm{O}$.

Embora existam estudos sobre nutrição mineral e recomendações de adubação para o cultivo comercial de alface, raramente se encontram trabalhos relacionados à produção de sementes, em que o ciclo de cultivo é bem maior. A escassez de informações relacionadas às exigências nutricionais pode limitar a obtenção de altas produtividades e interferir diretamente na qualidade das sementes produzidas. Kano (2006) ob- 
servou aumentos lineares na quantidade extraída de todos os macronutrientes pela cultura de alface para produção de sementes. Em áreas adubadas com fósforo foram observados aumentos na extração de 3,7 a 15 vezes, dependendo do nutriente considerado em relação aos resultados obtidos por Beninni (2005).

De acordo com Sá (1994), plantas adubadas de forma adequada produzem maiores quantidades de sementes e de melhor qualidade.

Harrington (1960), avaliando a germinação de sementes de alface, cenoura e de pimenta oriundas de plantas cultivadas sob severa deficiência de nutrientes, verificou que a deficiência de potássio ocasionou diminuição na produção de sementes e na porcentagem de sementes normais. Porém, Delouche (1980) ressalta que a resposta típica de plantas cultivadas em solo de baixa fertilidade relaciona-se mais a reduções na quantidade de sementes produzidas e não na qualidade.

O potássio em cobertura foi utilizado nesse trabalho visando suprir as necessidades da cultura para semente, cujo ciclo é muito superior àquele para a produção de "cabeça", pois se consideram duas etapas, uma vegetativa e outra reprodutiva.

Dada a situação apresentada anteriormente, conduziu-se este trabalho com o objetivo de avaliar a influência de doses de potássio nos teores de macronutrientes na matéria seca da parte aérea e nas sementes de plantas de alface.

\section{MATERIAL E MÉTODOS}

O trabalho foi conduzido na Fazenda Experimental São Manuel, pertencente à Faculdade de Ciências Agronômicas da UNESP em Botucatu-SP, localizada à latitude sul de $22^{\circ} 46^{\prime}$, longitude oeste de $48^{\circ} 34^{\prime}$ e altitude de $740 \mathrm{~m}$. A cultura de alface crespa, cultivar Verônica, foi conduzida em ambiente protegido por filme plástico, com estrutura tipo arco, de $20 \mathrm{~m}$ de comprimento, $7 \mathrm{~m}$ de largura e 3,8 m de altura, na parte mais alta e pé direito de $2,5 \mathrm{~m}$.

O delineamento experimental utilizado foi blocos casualizados, com cinco tratamentos $(0,0 ; 1,0 ; 1,5 ; 2,0$ e $2,5 \mathrm{~g}$ planta $^{-1}$ de $\mathrm{K}_{2} \mathrm{O}$ ) aplicando-se parte no plantio e o restante em cobertura. Foram utilizadas seis repetições por tratamento e a unidade experimental foi composta por seis plantas.

O solo utilizado foi Latossolo Vermelho Distrófico Típico (Embrapa, 1999) que apresentava as seguintes características: $\mathrm{pH}\left(\mathrm{CaCl}_{2}\right)=4,0 ; \mathrm{P}_{\text {resina }}=$ $2 \mathrm{mg} \mathrm{dm}^{-3}$; matéria orgânica $=2 \mathrm{~g} \mathrm{dm}^{-3}$; $\mathrm{V}(\%)=11$; e os valores de $\mathrm{H}+\mathrm{Al} ; \mathrm{K} ; \mathrm{Ca}$; $\mathrm{Mg}$; SB e CTC expressos em mmol $\mathrm{dm}^{-3}$ respectivamente de: $25 ; 1,2 ; 2,0 ; 1,0 ; 3,0$ e 28. A análise física desse solo indicou 761, 199 e $40 \mathrm{~g} \mathrm{~kg}^{-1}$ de areia, argila e silte, respectivamente.

A calagem foi realizada 30 dias antes do transplante das mudas, utilizando-se calcário de alta reatividade, de modo a elevar a saturação de bases a $80 \%$ e pH próximo de 6,0 conforme recomendações de Raij et al. (1996).

A adubação de plantio com nitrogênio e matéria orgânica também foram feitas de acordo com a análise química do solo e conforme proposta de Raij et al. (1996), considerando a produção comercial de alface "cabeça", isto é, aplicou-se 0,26 g planta $^{-1}$ de N na forma de sulfato de amônio e $500 \mathrm{~g}$ planta $^{-1}$ de composto orgânico comercial $\left(\right.$ Biomix $\left.^{\circledR}\right)$, como fonte de matéria orgânica. Quanto ao fósforo, (fornecido apenas no transplantio das mudas e utilizado o superfosfato triplo como fonte), utilizou-se a dose de 3,9 g planta $^{-1}$ de $\mathrm{P}_{2} \mathrm{O}_{5}$ que é $50 \%$ superior àquela recomendada por Raij et al. (1996), visando atender ao aumento da demanda por este nutriente, devido ao aumento do ciclo de cultivo e garantir o aumento na produtividade de sementes.

A análise química do composto orgânico comercial Biomix ${ }^{\circledR}$ indicou $\mathrm{pH}=7,7$ e valores de $\mathrm{MO} ; \mathrm{N} ; \mathrm{P}_{2} \mathrm{O}_{5}$; $\mathrm{K}_{2} \mathrm{O}$; $\mathrm{Ca} ; \mathrm{Mg}$ e de $\mathrm{S}$ expressos em \% respectivamente de $53 ; 1,30 ; 0,90 ; 0,47$; 6,$80 ; 0,25$ e 0,34 . A relação $\mathrm{C} / \mathrm{N}$ foi de $23 / 1$ e umidade $=60 \%$.

$\mathrm{Na}$ adubação de cobertura foram fornecidos o nitrogênio e o potássio. A adubação de cobertura com nitrogênio foi feita com nitrato de cálcio $(0,19 \mathrm{~g}$ planta $^{-1}$ de $\mathrm{N}$ por aplicação) e foram realizadas três aplicações aos 10, $18 \mathrm{e}$ aos 24 dias após o transplante (DAT), conforme recomendação de Raij et al.
(1996) para a produção de "cabeça". Após as plantas atingirem o ponto comercial de colheita (33 DAT), continuou-se com aplicações semanais de nitrogênio (mesma dose) até a colheita das sementes (121 DAT), totalizando a adubação com 3,5 g planta $^{-1}$ de N.

Quanto ao potássio, foi aplicado no plantio $1 \mathrm{~g}$ planta ${ }^{-1}$ de $\mathrm{K}_{2} \mathrm{O}$ utilizando-se como fonte o cloreto de potássio, exceto para o tratamento T1 (testemunha), de acordo com a recomendação de Raij et al. (1996), para uma população de 150 mil plantas ha-1 ${ }^{-1}$ Já em cobertura, o potássio (cloreto de potássio) foi fornecido em duas épocas: no ponto comercial para colheita da "cabeça" (33 DAT), e no início do florescimento (84 DAT), da seguinte forma: $\mathrm{T} 1=$ sem fornecimento de potássio; $\mathrm{T} 2=1 \mathrm{~g}^{\mathrm{g}}$ planta $^{-1}$ no ponto comercial para colheita da "cabeça" (C) e sem fornecimento no início do florescimento $(\mathrm{F}) ; \mathrm{T} 3=1 \mathrm{~g}^{\text {planta }}{ }^{-1}$ no $\mathrm{C}$ e 0,5 g planta $^{-1}$ no $\mathrm{F}$; T4= 1 g planta ${ }^{-1}$ no $\mathrm{C}$ e $1 \mathrm{~g} \mathrm{planta}^{-1}$ no F; e T5= $1 \mathrm{~g}$ planta $^{-1}$ no C e 1,5 g planta $^{-1}$ no F.

A semeadura foi realizada em bandejas de poliestireno no dia 17/02/04. Após a emergência procedeu-se o desbaste deixando apenas uma planta por célula da bandeja.

As mudas foram transplantadas em 24/03/04 para vasos de plástico com capacidade para 13 litros de solo e foram cultivadas, uma planta por vaso. $\mathrm{Na}$ estufa os vasos foram dispostos em seis linhas espaçados de 1,0 x 0,5 m.

As plantas foram tutoradas de modo a evitar o tombamento na fase reprodutiva e a irrigação foi realizada por gotejadores individuais instalados em cada vaso.

A colheita das sementes foi realizada manualmente no ponto de maturação fisiológica, conforme Reghin et al. (2000), iniciando-se aos 121 DAT e finalizando-se aos 141 DAT. Logo após a colheita, as sementes foram armazenadas e mantidas em câmara seca $\left(20^{\circ} \mathrm{C}\right.$ e $40 \%$ UR), até o início das análises.

Para a avaliação dos teores dos nutrientes (nitrogênio, fósforo, potássio, cálcio, magnésio e enxofre) na parte aérea das plantas de alface, foram coletadas duas plantas por parcela, no mesmo dia da última colheita de sementes.

As plantas coletadas foram encami- 
nhadas ao laboratório de análise química de plantas da UNESP, devidamente lavadas e secas em estufa com circulação forçada de ar e mantidas à temperatura constante de $65^{\circ} \mathrm{C}$, até atingirem massa constante, seguindo a metodologia descrita por Malavolta et al. (1997).

Após as determinações de massa, as amostras foram moídas em moinho tipo Wiley. A digestão sulfúrica foi utilizada para determinação de nitrogênio e a digestão nítrico-perclórica foi utilizada para determinação dos demais nutrientes (fósforo, potássio, cálcio, magnésio e enxofre), tanto na matéria seca da parte aérea (MSPA) como nas sementes, seguindo as metodologias apresentadas por Malavolta et al. (1997).

Os dados obtidos foram submetidos à análise de variância, teste $\mathrm{F}$ e análise de regressão para verificar o efeito de doses de potássio.

\section{RESULTADOS E DISCUSSÃO}

Os teores de potássio e de magnésio da matéria seca da parte aérea (MSPA) das plantas de alface coletadas no final do ciclo foram influenciados significativamente pelas doses de potássio. Entretanto, para os teores de nitrogênio, fósforo, cálcio e enxofre não foram verificados efeitos significativos (Tabela 1).

A ordem decrescente dos teores dos macronutrientes da MSPA foi $\mathrm{K}>\mathrm{N} \approx \mathrm{Ca}>\mathrm{Mg}>\mathrm{S} \approx \mathrm{P}$. Estes resultados estão parcialmente de acordo com Kano (2006), que ao avaliar o efeito de doses de $\mathrm{P}_{2} \mathrm{O}_{5}$ em plantas de alface cultivar Verônica para produção de sementes, verificou que a ordem decrescente dos teores de nutrientes na MSPA foi $\mathrm{K}>\mathrm{Ca} \approx \mathrm{N}>\mathrm{Mg}>\mathrm{P}>\mathrm{S}$. Beninni (2005) trabalhando com alface comercial (cultivar Verônica) para produção de folhas, também verificou maior teor de potássio na MSPA, seguido pelo teor de $\mathrm{N}, \mathrm{Ca}$, $\mathrm{P}, \mathrm{S}$ e $\mathrm{Mg}$.

Neste estudo, os teores médios ( $\mathrm{g}$ $\mathrm{kg}^{-1}$ ) de $\mathrm{N}, \mathrm{P}, \mathrm{K}, \mathrm{Ca}, \mathrm{Mg}$ e $\mathrm{S}$ na MSPA foram de $13 ; 1,0 ; 22 ; 12 ; 2,8$ e 1,0 , respectivamente (Tabela 1 ), valores semelhantes àqueles obtidos por Kano (2006), para a mesma cultivar, exceto para o teor de potássio.
Ao comparar os teores de nutrientes da MSPA obtidos neste estudo para a produção de sementes com os apresentados por Raij et al. (1996) nas folhas de alface para o consumo, observa-se que os teores de N, P, K, Ca, Mg e S ficaram abaixo da faixa considerada ideal por aqueles autores. Isto pode sugerir que, para a produção de sementes, os teores são diferentes daqueles encontrados em alface para o consumo de folhas, provavelmente devido ao estádio senescente das plantas ao final do ciclo reprodutivo.

O teor de potássio na MSPA aumentou linearmente com o aumento da dose de potássio aplicada (Figura 1A), indicando que a planta aumenta a absorção deste nutriente à medida que aumenta a disponibilidade do mesmo no solo. Já o teor de magnésio reduziu linearmente com o aumento da dose de potássio aplicada (Figura 1B). Estes resultados estão de acordo com o apresentado por
Malavolta et al. (1997), que explicam que altas concentrações de potássio no substrato podem inibir competitivamente a absorção de magnésio.

Quanto aos teores de macronutrientes contidos nas sementes, não houve efeito significativo de doses de potássio, verificado pelo teste $\mathrm{F}$ da análise de variância, para todos os nutrientes avaliados (Tabela 2). Entretanto foi possível observar a seguinte ordem decrescente dos teores de nutrientes: $\mathrm{N}>\mathrm{K}>\mathrm{P}>\mathrm{Mg}>\mathrm{Ca}>\mathrm{S}$. Estes resultados diferem daqueles obtidos por Kano (2006), principalmente em relação aos teores de fósforo e magnésio que foram maiores que os de potássio e de cálcio, respectivamente.

Lott et al. (1995), em uma revisão sobre várias culturas, descreveram também que entre os macronutrientes avaliados, o teor de nitrogênio nas sementes foi sempre maior que o dos demais nutrientes. Resultados seme-

Tabela 1. Teores médios de macronutrientes $\left(\mathrm{g} \mathrm{kg}^{-1}\right)$ na matéria seca da parte aérea das plantas de alface coletadas no final do ciclo (macronutrient content in dry matter of lettuce aboveground part harvested at the end of the crop cycle). São Manuel, UNESP, 2004.

\begin{tabular}{ccccccc}
\hline $\begin{array}{c}\text { Doses de potássio } \\
\left.\text { (g planta }^{-1} \text { de K }_{\mathbf{2}} \mathbf{O}\right)\end{array}$ & $\mathbf{N}$ & $\mathbf{P}$ & $\mathbf{K}$ & $\mathbf{C a}$ & $\mathbf{M g}$ & $\mathbf{S}$ \\
\hline $\mathrm{T} 1(0,0)$ & 13 & 1,0 & 14 & 12 & 3,1 & 1,1 \\
$\mathrm{~T} 2(1,0)$ & 13 & 1,0 & 20 & 12 & 3,0 & 1,1 \\
$\mathrm{~T} 3(1,5)$ & 13 & 0,9 & 22 & 13 & 3,1 & 1,1 \\
$\mathrm{~T} 4(2,0)$ & 13 & 1,0 & 25 & 12 & 2,6 & 1,2 \\
$\mathrm{~T} 5(2,5)$ & 11 & 0,9 & 27 & 12 & 2,4 & 1,1 \\
\hline $\mathrm{F}$ & $2,08^{\mathrm{ns}}$ & $1,69^{\mathrm{ns}}$ & $11,8^{* *}$ & $0,59^{\mathrm{ns}}$ & $4,12^{*}$ & $0,36^{\mathrm{ns}}$ \\
\hline $\mathrm{CV}(\%)$ & 14,8 & 12,9 & 16,5 & 14,5 & 14,2 & 12,1 \\
\hline
\end{tabular}

${ }^{\text {ns não significativo pelo teste } \mathrm{F} ; * * * * \text { significativo a } 5 \text { e a } 1 \% \text { de probabilidade pelo teste } \mathrm{F}}$ ( ${ }^{\mathrm{ns}}$ not significant by the $\mathrm{F}$ test; *;** significant at 5 and $1 \%$ of probability by the $\mathrm{F}$ test).

Tabela 2. Teores médios de macronutrientes $\left(\mathrm{g} \mathrm{kg}^{-1}\right)$ nas sementes de alface, em função de doses de potássio (average contens of macronutrients in lettuce seeds $\left(\mathrm{g} \mathrm{kg}^{-1}\right)$ depending on potassium rates). São Manuel, UNESP, 2004.

\begin{tabular}{ccccccc}
\hline $\begin{array}{c}\text { Doses de potássio } \\
\left.\text { (g planta }^{-1} \mathbf{d e ~ K}_{\mathbf{2}} \mathbf{O}\right)\end{array}$ & $\mathbf{N}$ & $\mathbf{P}$ & $\mathbf{K}$ & $\mathbf{C a}$ & $\mathbf{M g}$ & $\mathbf{S}$ \\
\hline $\mathrm{T} 1(0,0)$ & 38 & 5,8 & 6,3 & 2,0 & 3,0 & 1,8 \\
$\mathrm{~T} 2(1,0)$ & 41 & 6,1 & 6,0 & 1,9 & 3,1 & 1,8 \\
$\mathrm{~T} 3(1,5)$ & 44 & 6,4 & 6,1 & 2,0 & 3,1 & 1,7 \\
$\mathrm{~T} 4(2,0)$ & 43 & 5,7 & 6,1 & 1,9 & 3,0 & 1,7 \\
$\mathrm{~T} 5(2,5)$ & 43 & 6,1 & 6,2 & 1,8 & 3,1 & 1,7 \\
\hline $\mathrm{F}$ & $0,49^{\text {ns }}$ & $2,41^{\text {ns }}$ & $0,37^{\text {ns }}$ & $1,85^{\text {ns }}$ & $0,41^{\text {ns }}$ & $1,21^{\text {ns }}$ \\
\hline $\mathrm{CV}(\%)$ & 19,1 & 7,4 & 6,8 & 7,1 & 6,0 & 7,9 \\
\hline
\end{tabular}

${ }^{\mathrm{ns}}$ não significativo pelo teste $\mathrm{F}\left({ }^{\mathrm{ns}}\right.$ not significant by the $\mathrm{F}$ test). 


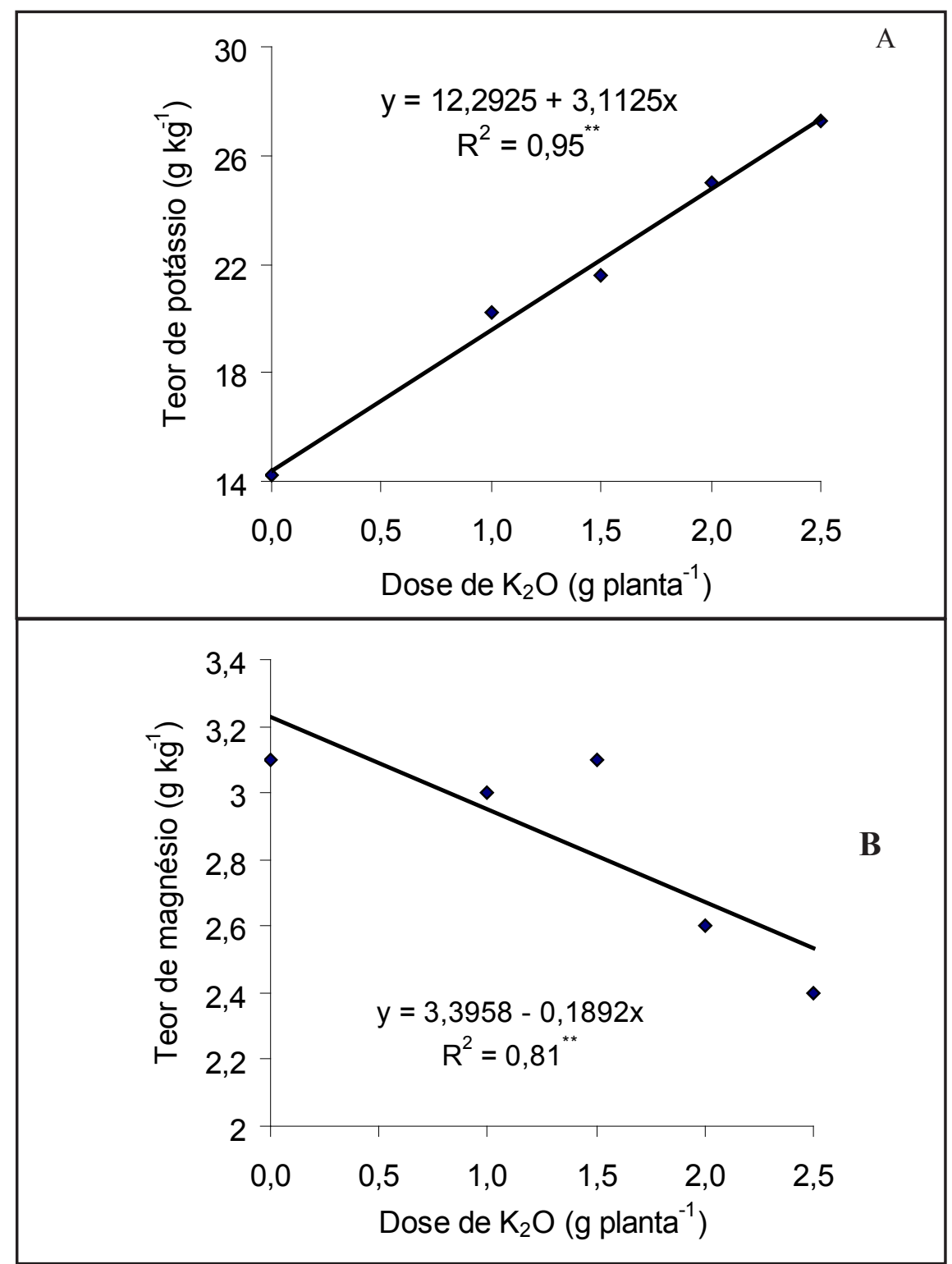

Figura 1. Teores de potássio (A) e magnésio (B) na matéria seca da parte aérea das plantas de alface coletadas no final do ciclo, em função de doses de $\mathrm{K}_{2} \mathrm{O}$ (potassium and magnesium content in dry matter of lettuce aboveground part harvested at the end of the crop cycle). São Manuel, UNESP, 2004.

lhantes foram obtidos com as sementes de feijão, por Vieira (1986) e por Ramos Júnior et al. (2003).

$\mathrm{O}$ teor de nitrogênio encontrado na semente foi cerca de três vezes superior àquele observado na MSPA(Tabelas $1 \mathrm{e}$ 2). Isso demonstra a importância deste elemento na composição da semente, geralmente rica em proteínas, além de ser um nutriente facilmente redistribuído na planta (Malavolta et al., 1997). Kano (2006), para essa mesma cultivar, também obteve maior teor de nitrogênio nas sementes do que no resto da parte aérea da planta. Entretanto,
Resultados semelhantes foram obtidos por Kano (2006). O teor de fósforo encontrado nas sementes ficou próximo daquele obtido por Carvalho (1978) que foi de $6,4 \mathrm{~g} \mathrm{~kg}^{-1}$. O maior teor de fósforo na semente pode ser justificado pelo fato deste nutriente ser armazenado como sais do ácido fítico, constituindo a fitina (Malavolta, 1980; Marschner, 1995; Lott et al., 1995).

Quanto ao potássio, os teores nas sementes foram cerca de 3,5 vezes inferiores àqueles observados na MSPA e não diferiram entre os tratamentos testados (Tabelas 1 e 2); resultado semelhante ao obtido por Kano (2006). Carvalho (1978) obteve em sementes de alface, teor médio de potássio nas sementes de $5,5 \mathrm{~g} \mathrm{~kg}^{-1}$, valor próximo ao obtido neste experimento (Tabela 2).

Da mesma forma que ocorre com o potássio, os teores de cálcio nas sementes foram cerca de seis vezes a menos que na MSPA (Tabelas 1 e 2), fato que segundo Malavolta et al. (1997) deve estar ligado à baixa mobilidade do cálcio no floema. Resultado semelhante também foi obtido por Kano (2006).

$\mathrm{O}$ teor de enxofre nas sementes foi ligeiramente superior àquele observado na MSPA (Tabelas 1 e 2), coincidindo com os resultados obtidos por Kano (2006).

Apesar da diminuição do teor de magnésio na MSPA em função das doses de potássio, nas sementes não foram observados efeitos dos tratamentos testados. Provavelmente este efeito se deve ao fato de ter ocorrido translocação de magnésio para as sementes, via mecanismos internos das plantas para garantir alta qualidade das sementes, tendo por fim a sobrevivência da espécie, como indicam Kano et al. (2006). Entretanto, Delouche (1980) ressalta que a resposta típica de plantas cultivadas em solo de baixa fertilidade é a redução na quantidade de sementes produzidas e não a sua qualidade.

Finalizando, pode-se concluir que os tratamentos testados (doses de potássio) não interferiram de forma significativa nos teores de macronutrientes das sementes, apesar de ter modificado os teores de potássio e de magnésio na matéria seca da parte aérea das plantas de alface, cultivar Verônica. 


\section{AGRADECIMENTOS}

À CAPES pela concessão da bolsa de doutorado à primeira autora e à FAPESP pelo auxílio financeiro (Processo 03/09637-0).

\section{REFERÊNCIAS}

BENINNI ERY; TAKAHASHI HW; NEVES CSVJ. 2005. Concentração e acúmulo de macronutrientes em alface cultivada em sistemas hidropônico e convencional. Semina 26: $273-282$

CARVALHO JL. 1978. Efeito da adubação nitrogenada sobre a produção e qualidade de sementes de alface (Lactuca sativa L.). Piracicaba: USP-ESALQ. 54p. (Tese mestrado).

CARVALHO NM; NAKAGAWA J. 2000. Sementes: ciência, tecnologia e produção. Jaboticabal: Funep. 588p.

DAVIS RM; SUBBARAO KV; RAID RN; KURTZ EA. 1997. Compendium of lettuce diseases. California: Academic Press. 79p.

DELOUCHE JC. 1980. Environmental effects on seed development and seed quality. HortScience 15: 775-780.

EMPRESA BRASILEIRA DE PESQUISA
AGROPECUÁRIA. 1999. Sistema brasileiro de classificação de solos. Brasília: Embrapa. 412p.

FILGUEIRA FAR. 2003. Asteráceas - Alface e outras hortaliças herbáceas. In: FILGUEIRA FAR (ed). Novo manual de olericultura: agrotecnologia moderna na produção e comercialização de hortaliças. Viçosa: UFV. p. 289-295.

HARRINGTON JF. 1960. Germination of seeds from carrot, lettuce and pepper plants grown under severe nutrient deficiencies. Journal of Agricultural Science 30: 219-235.

KANO C. 2006. Doses de fósforo no acúmulo de nutrientes, na produção e na qualidade de sementes de alface. Botucatu: UNESP-FCA. 112p. (Tese doutorado).

KANO C; CARDOSO AII; HIGUTI ARO; VILLAS BÔAS RL. 2006. Doses de potássio na produção e qualidade de sementes de alface. Horticultura Brasileira 24: 356-359.

LOTT JNA; GREENWOOD JS; BATTEN GD. 1995. Mechanisms and regulation of mineral nutrient storage during seed development. In: KIGEL J; GALILI G (eds). Seed development and germination. New York: Marcel Dekker. p.215-235.

MALAVOLTA E. 1980. Elementos de nutrição mineral de plantas. São Paulo: Agronômica Ceres. 251p.

MALAVOLTA E; VITTI GC; OLIVEIRA SA. 1997. Avaliação do estado nutricional das plantas, principios e aplicações. Piracicaba: Potafós. 319p.

MARSCHNER H. 1995. Mineral nutrition of higher plants. London: Academic Press. 889 p.

RAIJ B Van; CANTARELLA H; QUAGGIO JA; FURLANI AMC. 1996. Recomendações de adubação e calagem para o Estado de São Paulo. Campinas: Instituto Agronômico \& Fundação IAC. 285p.

RAMOS JÚNIOR EU; ZUCARELI C; PIRES NCC; NAKAGAWA J; FERNANDES DM. 2003. Adubação fosfatada e teores de nutrientes em sementes de feijão cultivar. IAC Carioca. In: CONGRESSO BRASILEIRO DE CIÊNCIA DO SOLO, 24. Resumos... Ribeirão Preto: SBCS (CD-ROM).

REGHIN MY; OTTO RF; ROCHA A. 2000. Indução do florescimento e produção de sementes de alface com diferentes doses de ácido giberélico. Horticultura Brasileira 18: 171-175.

SÁ ME. 1994. Importância da adubação na qualidade de sementes. In: SÁ ME; BUZZETI $\mathrm{S}$ (eds). Importância da adubação na qualidade dos produtos agrícolas. São Paulo: ÍCONE. p.65-98.

VIEIRA RF. 1986. Influência de teores de P no solo sobre a composição química, qualidade fisiológica e desempenho no campo de sementes de feijão (Phaseolus vulgaris L.). Ceres 33: 173-188. 